\title{
Exploring snake occurrence records: Spatial biases and marginal gains from accessible social media
}

\author{
Benjamin M Marshall ${ }^{\text {Corresp., } 1}$, Colin T Strine ${ }^{\text {Corresp. } 1}$ \\ ${ }^{1}$ School of Biology, Institute of Science, Suranaree University of Technology, Nakhon Ratchasima, Nakhon Ratchasima, Thailand \\ Corresponding Authors: Benjamin M Marshall, Colin T Strine \\ Email address: benjaminmichaelmarshall@gmail.com, strine.conservation@gmail.com
}

A species' distribution provides fundamental information on: climatic niche, biogeography, and conservation status. Species distribution models often use occurrence records from biodiversity databases, subject to spatial and taxonomic biases. Deficiencies in occurrence data can lead to incomplete species distribution estimates. We can incorporate other data sources to supplement occurrence datasets. The general public is creating -via GPSenabled cameras to photograph wildlife- incidental occurrence records that may present an opportunity to improve species distribution models. We investigated 1) occurrence data of a cryptic group of animals: non-marine snakes, in a biodiversity database: Global Biodiversity Information Facility (GBIF). And determined 2) whether incidental occurrence records extracted from geo-tagged social media images (Flickr) could improve distribution models for 18 tropical snake species. We provide $R$ code to search for and extract data from images using Flickr's API. We show the biodiversity database's 302,386 records disproportionately originate from North America, Europe and Oceania $(250,063,82.7 \%)$, with substantial gaps in tropical areas that host the highest snake diversity. North America, Europe and Oceania averaged several hundred records per species; whereas Asia, Africa and South America averaged less than 35 per species. Occurrence density showed similar patterns; Asia, Africa and South America have roughly ten-fold fewer records per $100 \mathrm{~km}^{2}$ than other regions. Social media provided 44,687 potential records. However, including them in distribution models only marginally impacted niche estimations; niche overlap indices were consistently over 0.9 . Similarly, we show negligible differences in Maxent model performance between models trained using GBIF-only and Flickr-supplemented datasets. Model performance appeared dependent on species, rather than number of occurrences or training dataset. We suggest that for tropical snakes, accessible social media currently fails to deliver appreciative benefits for estimating species distributions; but due to the variation between species and the rapid growth in social media data, may still be worth considering in future contexts. 
1 Exploring snake occurrence records:

2 Spatial biases and marginal gains from

3 accessible social media

4 Benjamin M. Marshall ${ }^{1 *}$, Colin T. Strine ${ }^{1 * *}$

$5{ }^{1}$ School of Biology, Institute of Science, Suranaree University of Technology, Nakhon

6 Ratchasima, Nakhon Ratchasima, Thailand

7

8 Corresponding author:

9 Benjamin M. Marshall

10 Colin T. Strine

11

12 Email address:

13 *benjaminmichaelmarshall@gmail.com

$14 * *$ strine.conservation@gmail.com 


\section{Abstract}

17 A species' distribution provides fundamental information on: climatic niche, biogeography, and conservation status. Species distribution models often use occurrence records from biodiversity databases, subject to spatial and taxonomic biases. Deficiencies in occurrence data can lead to incomplete species distribution estimates. We can incorporate other data sources to supplement occurrence datasets. The general public is creating -via GPS-enabled cameras to photograph wildlife- incidental occurrence records that may present an opportunity to improve species distribution models. We investigated 1) occurrence data of a cryptic group of animals: nonmarine snakes, in a biodiversity database: Global Biodiversity Information Facility (GBIF). And determined 2) whether incidental occurrence records extracted from geo-tagged social media images (Flickr) could improve distribution models for 18 tropical snake species. We provide R code to search for and extract data from images using Flickr's API. We show the biodiversity database's 302,386 records disproportionately originate from North America, Europe and Oceania $(250,063,82.7 \%)$, with substantial gaps in tropical areas that host the highest snake diversity. North America, Europe and Oceania averaged several hundred records per species; whereas Asia, Africa and South America averaged less than 35 per species. Occurrence density showed similar patterns; Asia, Africa and South America have roughly ten-fold fewer records per $100 \mathrm{~km}^{2}$ than other regions. Social media provided 44,687 potential records. However, including them in distribution models only marginally impacted niche estimations; niche overlap indices were consistently over 0.9. Similarly, we show negligible differences in Maxent model performance between models trained using GBIF-only and Flickr-supplemented datasets. Model performance appeared dependent on species, rather than number of occurrences or training dataset. We suggest that for tropical snakes, accessible social media currently fails to deliver appreciative benefits for estimating species distributions; but due to the variation between species and the rapid growth in social media data, may still be worth considering in future contexts.

\section{Introduction}

Species distribution models can yield insight into a species' niche and habitat (Santos et al., 2006). Information on a species' niche provides some ability to predict species' responses to environmental change (Penman et al., 2010; Yousefi et al., 2015; Ahmadi et al., 2019). Predictions from species distribution models can also inform protected area allocation (Tulloch et al., 2016), support conservation status assessments (Solano \& Feria, 2007; Fourcade et al., 2013), invasion potential (Pearson, 2015; Mutascio et al., 2018; although with complications Phillips, Chipperfield \& Kearney, 2008) and identify potential human-wildlife conflicts (YañezArenas et al., 2014).

The utility of a species distribution model is dependent on the underlying species occurrence data used in constructing the model. Gaps and incomplete data can lead to misidentifying the target species' niche (Monsarrat et al., 2019). Underestimating species distributions can further mask the impacts of human activity on distributions, contributing to shifting baseline syndrome - 
55

56

57

58

59

60

61

62

63

64

65

66

67

68

69

70

71

72

73

74

75

76

77

78

79

80

81

82

83

84

85

86

87

88

89

90

where progressively eroded species distributions or populations are accepted as normal or healthy (Cromsigt, Kerley \& Kowalczyk, 2012). Ways to mitigate data gaps need thorough investigation.

Technological advances, global survey effort and digitisation of museum records have developed large biodiversity databases, pulling together disparate data sources to make global occurrence records more accessible and comprehensive. However, considerable gaps in biodiversity databases exist because of: detection difficulties, inconsistent surveying, and inadequate (or sometimes inaccurate) locality data for museum specimens (Yesson et al., 2007; Beck et al., 2013; Troudet et al., 2017).

Supplementary novel data sources could help fill biodiversity database gaps (Toivonen et al., 2019). With the proliferation of GPS enabled devices, the public is generating huge datasets on Web 2.0 platforms that can describe and/or predict a variety of phenomena including: protests (Alanyali, Preis \& Moat, 2016), land-use (Antoniou et al., 2016), tourism (García-Palomares, Gutiérrez \& Mínguez, 2015; Chua et al., 2016), hurricane damage (Preis et al. 2013) and protected area use (Orsi \& Geneletti, 2013; Hausmann et al., 2018). Some Web 2.0 data, in the form of geo-tagged images, can communicate the identity and location of species (Barve, 2014). The Geo-tagged images in a searchable social media platform may be a source for incidentally collected records of species (Allain, 2019; Barve, 2014; ElQadi et al., 2017; Jiménez-Valverde et al., 2019).

Incidental biodiversity records have already improved data availability for butterflies, snowy owls (Barve, 2014), spiders (Jiménez-Valverde et al., 2019), bees, flowers (ElQadi et al., 2017) and turtles (Allain, 2019). But we do not know whether social media can provide similar benefits for (mostly) unpopular and low-detectability species.

Snakes present a model to explore the utility of social media data. Because snakes have been historically overlooked in research (Shine \& Bonnet, 2000; Miranda, 2017) and are difficult to detect (Steen, 2010; Durso \& Seigel, 2015) they are likely suffering from a lack of primary biodiversity data. The need to generate more primary biodiversity data is underscored by: snakes' important regulatory and keystone roles in ecosystem functioning (Willson \& Winne, 2016; Miranda, 2017); major gaps in reptile conservation assessments (Bland \& Böhm, 2016; Tingley, Meiri \& Chapple, 2016; Hughes, 2017); and frequent involvement in human-wildlife conflicts (Whitaker \& Shine, 2000; Akani et al., 2002; Meek, 2012; Miranda, Ribeiro- \& Strüssmann, 2016; Marshall et al., 2018).

We describe the current state of snake occurrence records in the Global Biodiversity Information Facility (GBIF) database, highlighting gaps in surveying. We then explore the potential utility of a supplementary data source, a photography sharing platform Flickr, in the modelling of tropical snake distributions. 


\section{Materials \& Methods}

92 We completed all data analysis in R v.3.5.3 (R Core Team, 2019) and R Studio v.1.2.1335 (R

93 Studio Team, 2019). For data visualisation we used ggplot2 (Wickham, 2016), ggrepel

94 (Slowikowski, 2018) and scico (Pedersen \& Crameri, 2018) packages. We have included a

95 directory of scripts, packages (using packrat (Ushey et al., 2018)), and data used in analysis at:

96 doi:10.5281/zenodo.3243983.

Data Retrieval

98

99

100

101

102

103

104

105

106

107

108

109

110

111

112

113

114

115

116

117

118

119 Flickr

120 To acquire data from Flickr we generated a list of species names, both common and binomial as

121

122

123

124

125

126

127

128

GBIF

Before acquiring data from the GBIF database (GBIF.org, 2019) we generated a comprehensive list of snake species. We used the taxize package (Chamberlain et al., 2018) to access GBIF and National Center for Biotechnology Information (NCBI; Benson, 2008; Sayer, 2009) records for all squamates families, filtering for those mentioning Serpentes in downstream classification. For each Serpentes family we then queried the GBIF database and downloaded occurrence records, on a per genus basis, using the dismo (Hijmans et al., 2017) and rgbif packages (Chamberlain et al., 2019). Once we had downloaded all records, we queried the GBIF database a second time to ensure that downloaded files were complete and included all available occurrences. All GBIF downloads and metadata (including a list of data sources) are available at doi:10.5281/zenodo.3243983.

After downloading, we compiled the resulting genus occurrence files, filtering out marine snake families (data manipulation performed with the dplyr (Wickham et al., 2017), data.table (Dowle \& Srinivasan, 2019) and reshape2 (Wickham, 2007) packages). Due to the size of the dataset, we automated cleaning. We opted to use the CoordinateCleaner package to clean each species individually (Zizka et al., 2019). Following the process outlined in Zizka et al. (2019), we removed records with locations as NAs, zeros, identical values, near GBIF headquarters, near biodiversity institutions, within oceans, and that were extreme outliers for that species (using interquartile range outlier detection). Species with over 15,000 records (e.g. Thamnophis spp., Natrix spp. and Vipera berus) failed or produced erroneous results so we examined these species manually, removing outlying occurrences (those occurring on incorrect continents). search terms. We used the taxize package (Chamberlain et al., 2018) to query the GBIF and NCBI databases for all species downstream of the Serpentes families. We then compiled results from both databases into a single list, removing duplicates. Common name queries of GBIF and NCBI databases were inadequate or failed for many species. Therefore, we created a query system that accessed The Reptile Database (Uetz et al., 2019) (using XML (Lang \& CRAN Team, 2019a), xml2 (Wickham, Hester \& Ooms, 2018) and rvest (Wickham, 2019)). For each species we retrieved all common names the Reptile Database listed. We parsed each set of common names to separate them to generate a list of search terms for each species, attempting to 
129 anticipate as many notation styles as possible used by Reptile Database. We relied on the stringr

130 package (Wickham, 2018) to handle recurring character patterns.

131 We then accessed Flickr's API (Flickr Development Team, 2019), via R packages XML (Lang \&

132 CRAN Team, 2019a), RCurl (Lang \& CRAN Team, 2019b) and httr (Wickham, 2017), using

133 each species' search terms to retrieve search results for images. Photos had to be tagged as snake

134 and geo-tagged so that a location was evident. During this process we saved a URL and year

135 (extracted with the lubridate package (Grolemund \& Wickham, 2011)) for each photo to later

136 manually verify species identification. We then manually reviewed each image for the 18

137 selected tropical species (1166 images total), removing records of non-target species or images

138 judged to have been taken within captive settings (captive settings were inferred by the presence

139 of artificial substrate, white-balances associated with artificial lighting and geographic proximity

140 to zoos, i.e. occurred within a raster cell and a suburban/urban area contiguous with a Google

141 Maps labelled zoo).

142 Raster Layers

143 We used the raster package (Hijmans, 2017) to retrieve climatic raster data from WorldClim

144 (Fick \& Hijmans, 2017). To guard against over-parameterisation and over-fitting during species

145 distribution modelling (Fourcade, Besnard \& Secondi, 2018), we discarded 14 of WorldClim's

146 bioclimatic layers. We discarded layers until between-layer correlations with an $\mathrm{R}$ value $>0.6$

147 were removed (Merow, Smith \& Silander, 2013; Castellanos et al., 2019). We explored different

148 combinations that reduced the correlation, and opted for a set of five variables covering a variety

149 of climatic aspects likely important to snake range delimitation (Kearney, Shine \& Porter, 2009;

150 Fourcade, Besnard \& Secondi, 2018). The remaining layers were: BIO1 (annual mean

151 temperature), $\mathrm{BIO} 2$ (mean diurnal temperature range), $\mathrm{BIO} 7$ (temperature annual range), $\mathrm{BIO} 12$

152 (annual precipitation), and BIO15 (precipitation seasonality).

153 We limited the remaining WorldClim data to three regions of interest: Tropical Asia (longitude:

154 50, 150; latitude: -25, 50), Africa (longitude: -40, 40; latitude: -25, 75) and South America

155 (longitude: -120, -25; latitude: -60, 25). We also downloaded global elevation data (Danielson \&

156 Gesch. 2011; U.S. Geological Survey, 2016.) and human footprint index (Venter et al. 2016a;

157 Venter et al. 2016b). Then we downscaled and reprojected elevation and footprint layers using

158 projectRaster (Hijmans, 2017) with the default bilinear method to match the regional WorldClim

159 layers' projection, extent and resolution. We have included the resulting raster layers used in

160 analysis in the supplementary data.

\section{Point Process Analysis}

162 We examined the distribution of GBIF occurrences via several point process analyses. We set the

163 data within a landmass polygon (to account for water bodies during calculations) downloaded

164 from natural earth using the rnaturalearth package (South, 2017). Then using the spatstat package

165 (Baddeley \& Turner, 2005) we tested for spatial conformity. We performed four types of spatial

166 tests. We ran quadrat tests (with quadrats roughly equivalent to 10 degrees squared) to examine

167 the spatial randomness of points. We calculated nearest neighbour distance functions $(\mathrm{G})$ with 
168 Kaplan-Meier, border, and hazard corrections to examine the distribution of distances from

169

170

171

172

173

174

175

176

177

178

179

180

181

182

183

184

185

186

187

188

189

190

191

192

193

194

195

196

197

198

199

200

201

202

203

204

205 points to their nearest neighbour. We estimated the empty space function (F) with Kaplan-Meier, border, and Chiu-Stoyan correction to examine how empty space is distributed between points. Finally, we estimated Ripley's reduced second moment function $(\mathrm{K})$, with no correction applied due to the prohibitively large dataset, for further examination of spatial non-randomness.

We estimated continental area and occurrence density using the rnaturalearth landmass. To estimate continental area, we projected the landmass for each continent using the closest Albers equal area conic projection (specifications obtained from https://epsg.io) with the rgeos (Bivand $\&$ Rundel, 2018) and sp packages (Pebesma et al., 2017). For standard error calculations we used the pracma (Borchers, 2018).

\section{Modelling}

Species selection

We selected 18 species to investigate: nine selected manually and nine selected randomly. Our manual selection was based on relative taxonomic stability, their charismatic appearance and ease of photographic identification: Bitis arietans MERREM, 1820; Bothriechis schlegelii (BERTHOLD, 1846); Bungarus fasciatus (SCHNEIDER, 1801); Calloselasma rhodostoma (KUHL, 1824); Coelognathus radiatus (BOIE, 1827); Dendroaspis polylepis GÜNTHER, 1864; Eunectes murinus (LINNAEUS, 1758); Malayopython reticulatus (SCHNEIDER, 1801); and Ophiophagus hannah (CANTOR, 1836). Our manual selection represented all three tropical regions (Tropical Asia: 5, Africa: 2, South America: 2).

In addition to the nine manually selected species, we used the sample $\mathrm{n}$ function in dplyr (Wickham et al., 2017) to randomly select nine more species that fitted the following criteria: occurs entirely within one of the three tropical regions, and be considered taxonomically stable. We defined the second criteria using the names listed on Reptile Database. Any species with a single binomial name listed since 2000, we considered stable. Once we had filtered the list of species by those criteria, we randomly selected nine species from 25 species with the most Flickr results. We had to repeat the random selection to avoid species with too few occurrences to model or an insufficiently sized distribution to be estimated with the resolution of raster layers. Porthidium spp. also had to be excluded because of the difficulties verifying species identity in images. The final nine randomly selected species were: Aplopeltura boa (BOIE, 1828); Atheris nitschei TORNIER, 1902; Boiga cynodon (BOIE, 1827); Boiga kraepelini STEJNEGER, 1902, Chironius carinatus (LINNAEUS, 1758); Echis coloratus GÜNTHER, 1878; Enhydris enhydris (SCHNEIDER, 1799); Hydrodynastes gigas (DUMÉRIL, BIBRON \& DUMÉRIL, 1854); and Sinonatrix percarinata (BOULENGER, 1899) (Tropical Asia: 5, Africa: 2, South America: 2).

\section{Model Settings}

We created four training datasets per species. First, we used SPthin (Aiello-Lammens et al., 2014) with a grid size equal to the raster cell to thin the data, ensuring only a single occurrence per cell. We split the GBIF occurrences into five randomly assigned groups in geographic space, 
206 limiting non-independence in environmental space (Roberts et al., 2017; Castellanos et al., 207 2019). We used the BlockCV package (Valavi et al., 2018) with the recommended block size 208 based on the climatic and elevation raster layers (using 100,000 samples, group assignment was

209 optimised across 500 iterations). Where the recommended block size failed to assign at least one 210 occurrence to every group, we decreased the block size by $5 \%$ and re-ran the assignment until all 211 groups were represented. Once groups had been successfully assigned, we set aside the median 212 sized group of points from testing. We used the remaining points to train the geo-independent 213 model. We generated a second GBIF data-only training set with a random subset of the original 214 data removed. We removed this subset with no space weighting (to replicate random k-folds 215 frequently used in the modelling literature), and the size was equal to the subset removed for the 216 geo-independent model training dataset. We refer to the second model as the GBIF random 217 model. The final models used the two GBIF training datasets described above supplemented by 218 the Flickr data collected for that species.

219 We generated an array of 10,000 background points for each species, the array was consistent 220 between model runs and training datasets. We bounded background point generation with a

221

222

223

224

225

226

227

228

229

230

231

232

233

234

235

236

237

238

239

240

241

242

243

244

minimum convex polygon around all species occurrence records (Castellanos et al., 2019), plus a buffer equal to half the mean distance between occurrences. Whereas studies usually choose a fixed buffer to create the bounding area, the disparity in our 18 species distributions required species-specific buffers based on relative occurrence record spread. Relying on a compromised fixed buffer for all species could underestimate AUC scores for species with large distributions, while inflating AUC scores for species with small distributions (Anderson \& Raza, 2010). Because survey effort is undocumented and unequal (Tulloch et al., 2013), we weighted background point distribution using a bias layer to areas that are likely to have had increased survey effort (Phillips et al., 2009; Merow, Smith \& Silander, 2013). We chose human footprint as proxy for survey likelihood, under the assumption that increased access and human presence will lead to greater occurrence records.

We used the ENMeval package (Muscarella et al., 2014) to run Maxent models across varying model settings. We chose Maxent because of its flexibility and performance relative to other methods (Elith et al., 2006). We used combinations of linear and quadratic feature classes and ran models using a sequence of regularization values from 1 to 8 to reduce the chances of overfitting (Shcheglovitova \& Anderson, 2013; Merow, Smith \& Silander, 2013; Radosavljevic \& Anderson, 2014) and set internal cross validation to user groups defined with BlockCV (Valavi et al., 2018).

\section{Model Evaluation}

The metrics used to assess species distribution model performance are debated. Due to their reliance on pseudo-absences some of the ways of evaluating models are unhelpful. We chose to follow Castellanos et al.'s, (2019) advice and use multiple metrics. We selected receiver operating characteristic AUC (ROC AUC) because of its wide use and ability to compare models based on different datasets. Use of ROC AUC has drawbacks (Lobo, Jiménez-valverde \& Real,

Peer) reviewing PDF | (2019:06:38771:1:1:NEW 25 Sep 2019) 
245 2008): it is sensitive to background area (Anderson \& Raza, 2010), and is liable to overestimate

246 model performance (Fernandes, Scherrer \& Guisan, 2018). To supplement ROC AUC

247 evaluation, we use precision-recall values (PRRC) -recently recommended as a metric

248 insensitive to background area and species rarity because it ignores correctly predicted absences

249 (Sofaer, Hoeting \& Jarnevich, 2019). For every model created by the four training datasets, we

250 calculated ROC AUC and PRRC values for all three test datasets with the PRROC package

251 (Grau, Grosse \& Keilwagen, 2015).

252 As an additional measure of the Flickr data's contribution to models, we examined the niche

253 overlap between models trained on only GBIF records and those trained on datasets

254 supplemented with Flickr occurrences. We estimated niche overlap using Schoener's D measure

255 with the ENMeval package (Muscarella et al., 2014).

256 We explored Maxent model performance using GLM and GLMMs with the lme4 package (Bates

257 et al., 2015). We created models using combinations of number of occurrences, species, and

258 training dataset as predictors of PRRC and ROC AUC values. The full list of models tested can

259 be found in Table S1. We used Spearman's rank test to explore the relationships between area

260 and occurrence count, after testing for normality with qqplots (from the car package (Fox \&

261 Weisberg, 2011)) and Shapiro-Wilk tests.

262 Results

263 Data Summary

264 Our assessments of GBIF snake occurrences reveal strong spatial bias in the 302,386 unique

265 locations of non-marine snakes. Flickr data searches produced only 44,689 images tagged with

266 snakes and location information; Flickr data was also spatially nonuniform.

267 All point process analysis showed that the distribution of GBIF and Flickr points are not

268 randomly distributed: multiple metrics suggest spatial clustering (GBIF data Quadrat test: X2 =

269 2425600, df =288, p-value <2.2e-16; Flickr: Quadrat test: X2 = 426820, df =288, p-value $<$

270 2.2e-16; G-function: Fig.S1; F-function: Fig.S2; K-function: Fig.S3). The clustering is apparent

271 in Fig.1 and Fig.2, illustrating points concentrated in North America, Europe and Australia -both

272 GBIF and Flickr appear to follow similar distributions.

273 Examining the GBIF results per continent reveals the scale of spatial bias (Table 1). The number

274 of occurrence records are considerably lower in Africa, Asia, and South America, despite their

275 large area and diversity of snake species. This pattern is particularly apparent in the density of

276 occurrence record estimates that are approximately ten-fold lower.

277 The data available for our 18 selected snake species varied dramatically (Fig.3), and appeared to

278 only be weakly positively associated with the size of the minimum convex polygon (MCP) of

279 occurrence points (Fig.4). Overall, we manually reviewed 1166 Flickr images, discarding 11.22

$280 \pm 5.68$ non-snake or captive image locations per species (range $=0-92$; percentage of images

281 discarded per species $11.06 \pm 4.86 \%$, range $=0-77.97 \%$ ). 


\section{Modelling Results}

283 Overall, we found that models trained on GBIF supplemented with Flickr results were

284 marginally better at predicting both randomly selected and geographically selected GBIF records 285 when assessed using ROC AUC (Fig.5). Precision-Recall values only saw the Flickr

286 supplemented models perform better when predicting the geographically independent sample of

287 GBIF records (Fig.6).

288 Models trained on randomly and geographically independent GBIF data performed similarly 289 when tested against the Flickr data. The randomly subset GBIF models showed more variable 290 results both for ROC AUC and PRRC. The respectable ability to predict Flickr results from only 291 GBIF records suggest that Flickr results have little in the way of new climatic information.

292 The limited new information provided by Flickr datasets is further supported by the high levels

293 of niche overlap between models trained on GBIF-only and Flickr-supplemented datasets, albeit

294 with variation between species (Fig.7).

295 When we investigated which variable predicts model performance, the mixed-models using the 296 training dataset and species as random predictors were superior based on AIC. The resulting 297 model agrees with Fig.1 and Fig.2 indicating variability between species and a weak trend driven 298 by the training dataset. While the model investigations seem to support species as the driver 299 behind Maxent model performance, the residuals from the models remain highly structured and 300 non-normal (Sharpiro-Wilk test: PRRC as response, $\mathrm{W}=0.7526$, $\mathrm{p}$-value $<2.2 \mathrm{e}-16$; ROC AUC 301 as response, $\mathrm{W}=0.94194$, $\mathrm{p}$-value $<2.2 \mathrm{e}-16$ ). Our models exploring change in model evaluation

302 metrics, suggested that the difference in sample size played a very small role (negative

303 relationship with PRRC values: $-0.0095 \pm 0.0039, \mathrm{p}=0.015$; positive relationship with ROC

304 AUC values: $0.0260 \pm 0.0042, p<0.001$ ) and the changes were largely dependent on the species

305 (model specification and AIC values can be found in Table S1).

\section{Discussion}

307 Spatial bias

308 Our results show a strong spatial bias in GBIF's occurrence records for non-marine snakes. The

309 lack of records in the critical snake hotspots mirrors investigations into other taxonomic groups

310 (Yesson et al., 2007; Amano, Lamming \& Sutherland, 2016; Roll et al., 2017). The identified

311 gaps in GBIF records support efforts to make use of more diverse data sources: by filling gaps in

312 GBIF coverage and boosting sample sizes, supplementary data sources could reduce the chances

313 of underestimating species distributions and ecological niches (Beck et al., 2013; Monsarrat et

314 al., 2019). However, while our efforts to retrieve occurrence records from social media were

315 successful, the quantity of records was insufficient to make significant impacts on distribution

316 models. The gaps in GBIF records (and similar gaps in Flickr derived data) are likely not the

317 results of lack of knowledge in these locations (Tantipisanuh \& Gale, 2018), but barriers limiting

318 submissions to global biodiversity databases (Amano \& Sutherland, 2013). 
319 Other studies had highlighted the potential of social media photographs to supplement existing 320 occurrence records (Allain, 2019; Barve, 2014; ElQadi et al., 2017), but stopped short of 321 exploring how the records would impact distribution modelling and model predictive power.

322 Studies that explored the impact on models' predictive power targeted more readily

323 photographed species in a region with greater interaction with biodiversity recording

324 (Jiménez-Valverde et al., 2019). Tropical snakes provide a harsher assessment of the utility of

325 community generated geo-tagged images. Our findings suggest that while there is a growing

326 potential for social media to supplement biodiversity databases, the benefits are currently

327 minimal for species with low-detectability and vary dramatically between species.

328 There are several reasons for researchers to consider using social media despite the marginal

329 impacts shown here. First, is the low cost of initially screening for potential records. Flickr's map

330 UI (https://www.flickr.com/map) can be used to gauge the number of potential records before

331 undertaking the task of extracting (and reviewing) the records. Second, are the benefits of

332 increased sample sizes that analyses of real-world data find difficult to quantify. Larger samples

333 are less sensitive to false-positives/negatives and locational error (Wisz et al., 2008; Mitchell,

334 Monk \& Laurenson, 2017; Fernandes, Scherrer \& Guisan, 2018). When working with species

335 with fewer than 20-30 records, model performance is more likely to be improved by any

336 additional records (Stockwell \& Peterson, 2002); only three of our tested species had fewer than

33730 records. Third, species distribution modelling techniques can vary in their sensitivity to

338 changes in sample size (Thibuad et al., 2014; Fernandes, Scherrer \& Guisan, 2018); Maxent

339 tends to be a less sensitive technique (Thibuad et al., 2014).

340 Supplementary data sources limitations and potential

341 We highlight three limitations to implementing social media occurrence into species distribution

342 efforts.

343 First is the number of geo-tagged images for low detectability species. The species with the most 344 photographs relative to GBIF records tended to be more striking, either in size or colouration

345 (e.g. Eunectes murinus, Malayopython reticulatus and Bothriechis schlegelii); a pattern reflected

346 in GBIF records overall (Troudet et al., 2017). Public interest in reptiles has also been linked to

347 whether a species is venomous, endangered, or widely distributed (Roll et al., 2016). It may be

348 the case that traits associated with people's interest in a species are mediated by traits that control

349 how likely a species is to be photographed, such as its rarity or natural history (e.g. generalist

350 species may be more photographed than purely cryptozoic species). Limitations associated with

351 the quantity of photos will lessen over time as GPS enabled cameras become more common and

352 the growth in geo-tagged images continues to increase (Fig.S4). Accessing other social media

353 platforms containing geo-tagged images could additionally bolster occurrence datasets. However,

354 current terms and conditions on several potential platforms prohibit data mining or have

355 significant barriers to data access (Toivonen et al., 2019). Reliance on manual curation of

356 occurrence records may be feasible when focusing on a single species but will become

357 prohibitively time-consuming when assessing a wider clade. 
358 The second limitation is the need to verify the identity of species depicted. While community 359 science projects can have good identification rates for non-professional participants (Austen et 360 al., 2016; Kosmala et al., 2016), species distribution modelling can be sensitive to false-positives 361 (Fernandes, Scherrer \& Guisan, 2018). Eliminating false-positives currently requires manual 362 verification by the researchers, but there is significant progress being made in automated species 363 identification (Botella et al., 2018; Wäldchen \& Mäder, 2018; Toivonen et al., 2019). For snakes, 364 a reliable system may be difficult to perfect given their crypsis and current taxonomic fluidity.

365 Even if automated photographic verification can become reasonably reliable, it would be prudent 366 to explicitly integrate the confidence of species identification into the distribution models, a

367 practice that has already been demonstrated to improve predictions (Louvrier et al., 2018;

368 Johnston et al., 2018).

369 Finally, researchers must consider the drivers behind different data sources distributions ( $\mathrm{Li}$,

370 Goodchild \& Xu, 2013). The use of bias layers in presence only modelling is the primary way to

371

372

373

374

375

376

377

378

379

380

381

382

383

384

385

386

387

388

389

390

391

392

393

394

395

396 mitigate the impacts of an unknowable survey effort (Phillips et al., 2009; Merow, Smith \& Silander, 2013). However, bias layers derived from the spatial patterns of one dataset may be inappropriate for another. This is why we opted for a bias layer, human footprint, that likely is connected to the overall distribution of wildlife observations. With larger datasets from more sources there may be a need to account for sampling bias on a per-dataset basis. Alternatively, social media derived datasets could be used only in model validation, proving a "semiindependent" dataset to supplement cross-validation (Gregr et al., 2019).

\section{Conservation implications}

Numerous reptiles lack proper conservation assessment due to data deficiency (Bland \& Böhm, 2016). Discovering ways to fill data gaps (e.g. Callaghan et al., 2019) without having to fund additional surveying efforts would be valuable at a time when natural history investigations are under appreciated but macro-ecological questions are popular (Ríos-Saldaña, Delibes-Mateos \& Ferreira, 2018; McCallen et al., 2019). Overcoming data deficiencies should be prioritised; delays could result in occurrence data derived from distributions defined by human activity (realised niche), rather than the climatic or absolute niche of a species (Monsarrat et al., 2019). Improvements in occurrence data may help identify current distributions, but unstructured occurrence data cannot help quantify population trends sorely needed for many reptile species (Bland \& Böhm, 2016; Bayraktarov et al., 2019).

The quantity and accessibility of social media species occurrence records is open for abuse. In herpetology there have been several cases of species being negatively affected by the scientific publication of location data (Stuart et al., 2006; Lindenmayer \& Scheele, 2017) even though journals allow masked or partial publication (Lowe et al., 2017). While there is understandable fear in publishing the locations of new and desirable species in scientific literature, how long does it take for that information to enter the public sphere via geo-tagged photography? With the rapid growth geo-tagged images, being able to keep a desirable species protected by secrecy or gate-keeping may become increasingly difficult. 
397 Conclusion

398 We have highlighted that there is significant spatial bias in the GBIF records for non-marine 399 snakes, with gaps in tropical regions that house exceptionally high snake diversity (Roll et al., 400 2017). While we encourage the investigation of supplementary data sources to help fill gaps in 401 biodiversity databases, currently accessible social media occurrence records only improve 402 species distribution models marginally. The data availability for tropical snakes is highly variable 403 between species and emphasises the difficulties researchers face when studying low detectability 404 species. Both GBIF and social media data sources are growing exponentially (although not 405 uniformly across taxa [Amano, Lamming \& Sutherland, 2016]); tapping the full potential of 406 these resources may be best realised with integration of image recognition and identification 407 confidence.

408 Acknowledgements

409 We thank the Suranaree University of Technology for providing the resources required to 410 undertake this research. We thank Inês Silva and Matt Crane for enduring long discussions on 411 model evaluation metrics. We thank the Flickr team for creating an API that is accessible and 412 searchable. Finally, we thank countless photographers across the globe for their enthusiasm for 413 wildlife. We would also like to thank the editor, Assoc. Prof. Alastair Culham, and three 414 anonymous reviewers for their comments and insight in improving this manuscript.

\section{References}

417 Ahmadi M, Hemami M-R, Kaboli M, Malekian M, Zimmermann NE. 2019. Extinction risks of a Mediterranean neo-endemism complex of mountain vipers triggered by climate change. Scientific Reports 9:6332. DOI: 10.1038/s41598-019-42792-9.

Aiello-Lammens ME, Boria RA, Radosavljevic A, Vilela B, Anderson RP. 2014. spThin: Functions for Spatial Thinning of Species Occurrence Records for Use in Ecological Models. anthropogenic mortality of suburban snakes in an African tropical region. Israel Journal of Zoology 48:1-11. DOI: 10.1092/NL55-UK13-XXQ9-NCYE.

Alanyali M, Preis T, Moat HS. 2016. Tracking Protests Using Geotagged Flickr Photographs. PLOS ONE 11:e0150466. DOI: 10.1371/journal.pone.0150466. 
428 Allain S. 2019. Mining Flickr: a method for expanding the known distribution of invasive 429 species. Herpetological Bulletin:11-14. DOI: $10.33256 /$ hb148.1114.

430 Amano T, Lamming JDL, Sutherland WJ. 2016. Spatial Gaps in Global Biodiversity Information 431 and the Role of Citizen Science. BioScience 66:393-400. DOI: 10.1093/biosci/biw022.

432

433

434 435 436

Amano T, Sutherland WJ. 2013. Four barriers to the global understanding of biodiversity conservation: wealth, language, geographical location and security. Proceedings of the Royal Society B: Biological Sciences 280:20122649. DOI: 10.1098/rspb.2012.2649.

Anderson RP, Raza A. 2010. The effect of the extent of the study region on GIS models of species geographic distributions and estimates of niche evolution: Preliminary tests with montane rodents (genus Nephelomys) in Venezuela. Journal of Biogeography 37:13781393. DOI: 10.1111/j.1365-2699.2010.02290.x.

Antoniou V, Fonte C, See L, Estima J, Arsanjani J, Lupia F, Minghini M, Foody G, Fritz S. 2016. Investigating the Feasibility of Geo-Tagged Photographs as Sources of Land Cover Input Data. ISPRS International Journal of Geo-Information 5:64. DOI: 10.3390/ijgi5050064.

Austen GE, Bindemann M, Griffiths RA, Roberts DL. 2016. Species identification by experts and non-experts: comparing images from field guides. Scientific Reports 6:33634. DOI: $10.1038 /$ srep33634.

Baddeley A, Turner R. 2005. spatstat: An R Package for Analyzing Spatial Point Patterns. Journal of Statistical Software 12:1-42.

Barve V. 2014. Discovering and developing primary biodiversity data from social networking sites: A novel approach. Ecological Informatics 24:194-199. DOI: 10.1016/j.ecoinf.2014.08.008. 
451 Bates D, Mächler M, Bolker B, Walker S. 2015. Fitting Linear Mixed-Effects Models Using 452 lme4. Journal of Statistical Software 67:1-48. DOI: 10.18637/jss.v067.i01.

453 Bayraktarov E, Ehmke G, O’Connor J, Burns EL, Nguyen HA, McRae L, Possingham HP, 454 Lindenmayer DB. 2019. Do Big Unstructured Biodiversity Data Mean More Knowledge? 455 Frontiers in Ecology and Evolution 6:239. DOI: 10.3389/fevo.2018.00239.

456 Beck J, Ballesteros-Mejia L, Nagel P, Kitching IJ. 2013. Online solutions and the 'Wallacean 457 shortfall': what does GBIF contribute to our knowledge of species' ranges? Diversity and Distributions 19:1043-1050. DOI: 10.1111/ddi.12083.

Benson, DA, Karsch-Mizrachi, I, Lipman, DJ, Ostell, J, \& Wheeler, DL. (2008). GenBank Nucleic Acids Res. Jan, 1, 33.

461 https://www.ncbi.nlm.nih.gov/Taxonomy/taxonomyhome.html/ 204:16-22. DOI: 10.1016/j.biocon.2016.05.018.

Borchers HW. 2018. pracma: Practical Numerical Math Functions.

466 Botella C, Joly A, Bonnet P, Monestiez P, Munoz F. 2018. Species distribution modeling based on the automated identification of citizen observations. Applications in Plant Sciences 6:e1029. DOI: 10.1002/aps3.1029.

469 Callaghan CT, Rowley JJL, Cornwell WK, Poore AGB, Major RE. 2019. Improving big citizen science data: Moving beyond haphazard sampling. PLOS Biology 17:e3000357. DOI: 10.1371/journal.pbio.3000357. 
472 Castellanos AA, Huntley JW, Voelker G, Lawing AM. 2019. Environmental filtering improves

473 ecological niche models across multiple scales. Methods in Ecology and Evolution

474 10:481-492. DOI: 10.1111/2041-210X.13142.

475 Chamberlain S, Barve V, Mcglinn D, Oldoni D, Desmet P, Geffert L, Ram K. 2019. rgbif:

476 Interface to the Global Biodiversity Information Facility API.

477 Chamberlain S, Szoecs E, Foster Z, Arendsee Z, Boettiger C, Ram K, Bartomeus I, Baumgartner 478 J, O’Donnell J, Oksanen J, Tzovaras BG, Marchand P, Tran V. 2018. taxize: Taxonomic information from around the web.

480 Chua A, Servillo L, Marcheggiani E, Moere AV. 2016. Mapping Cilento: Using geotagged social 481 482 media data to characterize tourist flows in southern Italy. Tourism Management 57:295310. DOI: 10.1016/j.tourman.2016.06.013.

483 Cromsigt JPGM, Kerley GIH, Kowalczyk R. 2012. The difficulty of using species distribution 484 485 modelling for the conservation of refugee species - the example of European bison. Diversity and Distributions 18:1253-1257. DOI: 10.1111/j.1472-4642.2012.00927.x.

Danielson, JJ, and Gesch, DB. 2011. Global multi-resolution terrain elevation data 2010 (GMTED2010): U.S. Geological Survey Open-File Report 2011-1073. http://pubs.usgs.gov/of/2011/1073/pdf/of2011-1073.pdf

Dowle M, Srinivasan A. 2019. data.table: Extension of 'data.frame`.

Durso AM, Seigel RA. 2015. A Snake in the Hand is Worth 10,000 in the Bush. Journal of Herpetology 49:503-506. DOI: 10.1670/15-49-04.1.

Elith J, H. Graham C, P. Anderson R, Dudík M, Ferrier S, Guisan A, J. Hijmans R, Huettmann F, 493 R. Leathwick J, Lehmann A, Li J, G. Lohmann L, A. Loiselle B, Manion G, Moritz C, Nakamura M, Nakazawa Y, McC. M. Overton J, Townsend Peterson A, J. Phillips S, 
495

496

497

498

499

500

501

502

503

504

505

506

507

508

509

510

511

512

513

514 Fox J, Weisberg S. 2011. An R Companion to Applied Regression. Thousand Oaks CA: Sage.

515 García-Palomares JC, Gutiérrez J, Mínguez C. 2015. Identification of tourist hot spots based on 516

Richardson K, Scachetti-Pereira R, E. Schapire R, Soberón J, Williams S, S. Wisz M, E. Zimmermann N. 2006. Novel methods improve prediction of species' distributions from occurrence data. Ecography 29:129-151. DOI: 10.1111/j.2006.0906-7590.04596.x.

ElQadi MM, Dorin A, Dyer A, Burd M, Bukovac Z, Shrestha M. 2017. Mapping species distributions with social media geo-tagged images: Case studies of bees and flowering plants in Australia. Ecological Informatics 39:23-31. DOI: 10.1016/j.ecoinf.2017.02.006.

Fernandes RF, Scherrer D, Guisan A. 2018. Effects of simulated observation errors on the performance of species distribution models. Diversity and Distributions:1-14. DOI: 10.1111/ddi.12868.

Flickr Development Team. 2019. Flickr API. https://www.flickr.com/services/api/

Fick, SE, Hijmans, RJ. 2017. Worldclim 2: New 1-km spatial resolution climate surfaces for global land areas. International Journal of Climatology.

Fourcade Y, Engler JO, Besnard AG, Rödder D, Secondi J. 2013. Confronting expert-based and modelled distributions for species with uncertain conservation status: A case study from the corncrake (Crex crex). Biological Conservation 167:161-171. DOI: 10.1016/j.biocon.2013.08.009.

Fourcade Y, Besnard AG, Secondi J. 2018. Paintings predict the distribution of species, or the challenge of selecting environmental predictors and evaluation statistics. Global Ecology and Biogeography 27:245-256. DOI: 10.1111/geb.12684. social networks: A comparative analysis of European metropolises using photo-sharing services and GIS. Applied Geography 63:408-417. DOI: 10.1016/j.apgeog.2015.08.002. 
518 GBIF.org. 2019. Global Biodiversity Information Facility Website. https://www.gbif.org [05-08

$519 \quad$ April 2019].

520 Grau J, Grosse I, Keilwagen J. 2015. PRROC: computing and visualizing precision-recall and

521 receiver operating characteristic curves in R. Bioinformatics 31:2595-2597.

522 Gregr EJ, Palacios DM, Thompson A, Chan KMA. 2019. Why less complexity produces better forecasts: an independent data evaluation of kelp habitat models. Ecography 42:428-443. DOI: $10.1111 /$ ecog.03470.

Grolemund G, Wickham H. 2011. Dates and Times Made Easy with lubridate. Journal of Statistical Software 40:1-25.

Hausmann A, Toivonen T, Slotow R, Tenkanen H, Moilanen A, Heikinheimo V, Di Minin E. 2018. Social Media Data Can Be Used to Understand Tourists' Preferences for NatureBased Experiences in Protected Areas: Social media data in protected areas. Conservation Letters 11:e12343. DOI: 10.1111/conl.12343.

531 Hijmans RJ. 2017. raster: Geographic Data Analysis and Modeling.

532 Hijmans RJ, Phillips S, Leathwick J, Elith J. 2017. dismo: Species Distribution Modeling.

533 Hughes AC. 2017. Mapping priorities for conservation in Southeast Asia. Biological 534 Conservation 209:395-405. DOI: 10.1016/j.biocon.2017.03.007.

535 Jiménez-Valverde A, Peña-Aguilera P, Barve V, Burguillo-Madrid L. 2019. Photo-sharing 536 platforms key for characterising niche and distribution in poorly studied taxa. Insect 537 Conservation and Diversity:icad.12351. DOI: 10.1111/icad.12351.

538 Johnston A, Fink D, Hochachka WM, Kelling S. 2018. Estimates of observer expertise improve 539 species distributions from citizen science data. Methods in Ecology and Evolution 9:8854097. DOI: $10.1111 / 2041-210 X .12838$. 
541 Kearney M, Shine R, Porter WP. 2009. The potential for behavioral thermoregulation to buffer

542 "cold-blooded" animals against climate warming. Proceedings of the National Academy

543 of Sciences 106:3835-3840. DOI: 10.1073/pnas.0808913106.

544 Kosmala M, Wiggins A, Swanson A, Simmons B. 2016. Assessing data quality in citizen

545 science. Frontiers in Ecology and the Environment 14:551-560. DOI: 10.1002/fee.1436.

546 Lang DT, CRAN Team. 2019a. XML: Tools for Parsing and Generating XML Within R and S-

$547 \quad$ Plus.

548 Lang DT, CRAN Team. 2019b. RCurl: General Network (HTTP/FTP/...) Client Interface for R.

549 Li L, Goodchild MF, Xu B. 2013. Spatial, temporal, and socioeconomic patterns in the use of

$550 \quad$ Twitter and Flickr. Cartography and Geographic Information Science 40:61-77. DOI:

$551 \quad 10.1080 / 15230406.2013 .777139$.

552 Lindenmayer D, Scheele B. 2017. Do not publish. Science 356:800-801. DOI:

$553 \quad 10.1126 /$ science.aan1362.

554 Lobo JM, Jiménez-valverde A, Real R. 2008. AUC: A misleading measure of the performance of 555 predictive distribution models. Global Ecology and Biogeography 17:145-151. DOI:

$556 \quad 10.1111 / \mathrm{j} .1466-8238.2007 .00358 . x$.

557 Louvrier J, Molinari-Jobin A, Kéry M, Chambert T, Miller D, Zimmermann F, Marboutin E,

558 Molinari P, Müeller O, Černe R, Gimenez O. 2018. Use of ambiguous detections to

559 improve estimates from species distribution models. Conservation Biology 33:185-195.

$560 \quad$ DOI: $10.1111 /$ cobi.13191.

561 Lowe AJ, Smyth AK, Atkins K, Avery R, Belbin L, Brown N, Budden AE, Gioia P, Guru S,

562 Hardie M, Hirsch T, Hobern D, La Salle J, Loarie SR, Miles M, Milne D, Nicholls M, 

but responsibly. Science 357:141-141. DOI: 10.1126/science.aao0054.

565 Marshall BM, Strine CT, Jones MD, Theodorou A, Amber E, Waengsothorn S, Suwanwaree P, Goode M. 2018. Hits Close to Home: Repeated Persecution of King Cobras

McCallen E, Knott J, Nunez-Mir G, Taylor B, Jo I, Fei S. 2019. Trends in ecology: shifts in ecological research themes over the past four decades. Frontiers in Ecology and the Environment. DOI: 10.1002/fee.1993.

Meek R. 2012. Anthropogenic sources of mortality in the western whip snake, Hierophis viridiflavus, in a fragmented landscape in Western France. Herpetological Bulletin

Merow C, Smith MJ, Silander JA. 2013. A practical guide to MaxEnt for modeling species' distributions: what it does, and why inputs and settings matter. Ecography 36:1058-1069.

Miranda EBP de. 2017. The Plight of Reptiles as Ecological Actors in the Tropics. Frontiers in DOI: $10.1111 /$ j.1600-0587.2013.07872.x. Ecology and Evolution 5:159. DOI: 10.3389/fevo.2017.00159.

Miranda EBP, Ribeiro- RP, Strüssmann C. 2016. The ecology of human-anaconda conflict: a 581 study using internet videos. Tropical Conservation Science 9:43-77. DOI: $10.1177 / 194008291600900105$.

Mitchell PJ, Monk J, Laurenson L. 2017. Sensitivity of fine-scale species distribution models to 584 locational uncertainty in occurrence data across multiple sample sizes. Methods in Ecology and Evolution 8:12-21. DOI: 10.1111/2041-210X.12645. 
586 Monsarrat S, Novellie P, Rushworth I, Kerley GIH. 2019. Shifted distribution baselines:

587 neglecting long-term biodiversity records risks overlooking potentially suitable habitat 588 for conservation management. bioRxiv. DOI: $10.1101 / 565929$.

589 Muscarella R, Galante PJ, Soley-Guardia M, Boria RA, Kass JM, Uriarte M, Anderson RP. 590 2014. ENMeval: An R package for conducting spatially independent evaluations and estimating optimal model complexity for Maxent ecological niche models. Methods in

Mutascio HE, Pittman SE, Zollner PA, D’Acunto LE. 2018. Modeling relative habitat suitability of southern Florida for invasive Burmese pythons (Python molurus bivittatus). Landscape Ecology 33:257-274. DOI: 10.1007/s10980-017-0597-5.

Orsi F, Geneletti D. 2013. Using geotagged photographs and GIS analysis to estimate visitor flows in natural areas. Journal for Nature Conservation 21:359-368. DOI:

601

602 10.1016/j.jnc.2013.03.001.

Pearson RG. 2015. Asian common toads in Madagascar: An urgent effort to inform surveys and eradication efforts. Global Change Biology 21:9-9. DOI: 10.1111/gcb.12693.

603 Pedersen TL, Crameri F. 2018. scico: Colour Palettes Based on the Scientific Colour-Maps. 604 Penman TD, Pike DA, Webb JK, Shine R. 2010. Predicting the impact of climate change on 605 606 Australia's most endangered snake, Hoplocephalus bungaroides: Impact of climate 607 change on an endangered snake. Diversity and Distributions 16:109-118. DOI:

607 10.1111/j.1472-4642.2009.00619.x. 
608 Phillips BL, Chipperfield JD, Kearney MR. 2008. The toad ahead: Challenges of modelling the

609

610

611

612

613

614

615

616

617

618

619

620

621

622

623

624

625

626

627

628

629

range and spread of an invasive species. Wildlife Research 35:222-234. DOI: 10.1071/WR07101.

Phillips SJ, Dudík M, Elith J, Graham CH, Lehmann A, Leathwick J, Ferrier S. 2009. Sample selection bias and presence-only distribution models: implications for background and pseudo-absence data. Ecological Applications 19:181-197. DOI: 10.1890/07-2153.1.

Preis T, Moat HS, Bishop SR, Treleaven P, Stanley HE. 2013. Quantifying the Digital Traces of Hurricane Sandy on Flickr. Scientific Reports 3:3141. DOI: 10.1038/srep03141.

R Core Team. 2019. R: A language and environment for statistical computing. Vienna, Austria: R Foundation for Statistical Computing.

R Studio Team. 2019. RStudio: Integrated Development Environment for R. Boston, MA: RStudio, Inc.

Radosavljevic A, Anderson RP. 2014. Making better Maxent models of species distributions: Complexity, overfitting and evaluation. Journal of Biogeography 41:629-643. DOI: 10.1111/jbi.12227.

Ríos-Saldaña CA, Delibes-Mateos M, Ferreira C. 2018. Are fieldwork studies being relegated to second place in conservation science? Global Ecology and Conservation:e00389. DOI: 10.1016/j.gecco.2018.e00389.

Roberts DR, Bahn V, Ciuti S, Boyce MS, Elith J, Guillera-Arroita G, Hauenstein S, LahozMonfort JJ, Schröder B, Thuiller W, Warton DI, Wintle BA, Hartig F, Dormann CF. 2017. Cross-validation strategies for data with temporal, spatial, hierarchical, or phylogenetic structure. Ecography 40:913-929. DOI: 10.1111/ecog.02881. 
630 Roll U, Mittermeier JC, Diaz GI, Novosolov M, Feldman A, Itescu Y, Meiri S, Grenyer R. 2016.

631 Using Wikipedia page views to explore the cultural importance of global reptiles.

632 Biological Conservation 204:42-50. DOI: 10.1016/j.biocon.2016.03.037.

633 Roll U, Feldman A, Novosolov M, Allison A, Bauer AM, Bernard R, Böhm M, Castro-Herrera

634 F, Chirio L, Collen B, Colli GR, Dabool L, Das I, Doan TM, Grismer LL, Hoogmoed M, 635 Itescu Y, Kraus F, LeBreton M, Lewin A, Martins M, Maza E, Meirte D, Nagy ZT, de C.

636 Nogueira C, Pauwels OSG, Pincheira-Donoso D, Powney GD, Sindaco R, Tallowin OJS,

637 Torres-Carvajal O, Trape J-F, Vidan E, Uetz P, Wagner P, Wang Y, Orme CDL, Grenyer

638 R, Meiri S. 2017. The global distribution of tetrapods reveals a need for targeted reptile

639 conservation. Nature Ecology \& Evolution 1:1677-1682. DOI: 10.1038/s41559-017-

$640 \quad$ 0332-2.

641 Santos X, Brito JC, Sillero N, Pleguezuelos JM, Llorente GA, Fahd S, Parellada X. 2006.

642 Inferring habitat-suitability areas with ecological modelling techniques and GIS: A

643 contribution to assess the conservation status of Vipera latastei. Biological Conservation

644 130:416-425. DOI: 10.1016/j.biocon.2006.01.003.

645 Sayers, E. W. 2009. Barrett T, Benson DA, Bryant SH, Canese K, Chetvernin V, Church DM,

646 DiCuccio M, Edgar R, Federhen S, Feolo M, Geer LY, Helmberg W, Kapustin Y,

647 Landsman D, Lipman DJ, Madden TL, Maglott DR, Miller V, Mizrachi I, Ostell J, Pruitt

648 KD, Schuler GD, Sequeira E, Sherry ST, Shumway M, Sirotkin K, Souvorov A,

649 Starchenko G, Tatusova TA, Wagner L, Yaschenko E, Ye J. Database resources of the

650 National Center for Biotechnology Information. Nucl Acids Res. 37, D5-D15.

651 https://www.ncbi.nlm.nih.gov/Taxonomy/taxonomyhome.html/ 
652 Shcheglovitova M, Anderson RP. 2013. Estimating optimal complexity for ecological niche

653

654

655

656

657

658

659

660

661

662

663

664

665

666

667

668

669

670

671

672

models: A jackknife approach for species with small sample sizes. Ecological Modelling 269:9-17. DOI: 10.1016/j.ecolmodel.2013.08.011.

Shine R, Bonnet X. 2000. Snakes: a new "model organism" in ecological research? Trends in Ecology and Evolution 15:221-222.

Slowikowski K. 2018. ggrepel: Automatically Position Non-Overlapping Text Labels with "ggplot2."

Sofaer HR, Hoeting JA, Jarnevich CS. 2019. The area under the precision-recall curve as a performance metric for rare binary events. Methods in Ecology and Evolution 10:565577. DOI: $10.1111 / 2041-210 X .13140$.

Solano E, Feria TP. 2007. Ecological niche modeling and geographic distribution of the genus Polianthes L. (Agavaceae) in Mexico: using niche modeling to improve assessments of risk status. Biodiversity and Conservation 16:1885-1900. DOI: 10.1007/s10531-0069091-0.

South A. 2017. rnaturalearth: World Map Data from Natural Earth.

Steen DA. 2010. Snakes in the grass: Secretive natural histories defy both conventional and progressive statistics. Herpetological Conservation and Biology 5:183-188.

Stockwell DRB, Peterson AT. 2002. Effects of sample size on accuracy of species distribution models. Ecological Modelling 148:1-13. DOI: 10.1016/S0304-3800(01)00388-X.

Stuart BL, Rhodin AGJ, Grismer LL, Hansel T. 2006. Scientific description can imperil species. Science 312:1137. DOI: 10.1126/science.312.5777.1137b.

Peer) reviewing PDF | (2019:06:38771:1:1:NEW 25 Sep 2019) 
673 Tantipisanuh N, Gale GA. 2018. Identification of biodiversity hotspot in national level -

674 Importance of unpublished data. Global Ecology and Conservation 13:e00377. DOI:

$675 \quad$ 10.1016/j.gecco.2018.e00377.

676 Thibaud E, Petitpierre B, Broennimann O, Davison AC, Guisan A. 2014. Measuring the relative

677 effect of factors affecting species distribution model predictions. Methods in Ecology and

678 Evolution 5:947-955. DOI: 10.1111/2041-210X.12203.

679 Tingley R, Meiri S, Chapple DG. 2016. Addressing knowledge gaps in reptile conservation.

680 Biological Conservation 204:1-5. DOI: 10.1016/j.biocon.2016.07.021.

681 Toivonen T, Heikinheimo V, Fink C, Hausmann A, Hiippala T, Järv O, Tenkanen H, Di Minin

682 E. 2019. Social media data for conservation science: A methodological overview.

683 Biological Conservation 233:298-315. DOI: 10.1016/j.biocon.2019.01.023.

684 Troudet J, Grandcolas P, Blin A, Vignes-Lebbe R, Legendre F. 2017. Taxonomic bias in

685 biodiversity data and societal preferences. Scientific Reports 7:9132. DOI:

$686 \quad 10.1038 / \mathrm{s} 41598-017-09084-6$.

687 Tulloch AIT, Mustin K, Possingham HP, Szabo JK, Wilson KA. 2013. To boldly go where no

688 volunteer has gone before: predicting volunteer activity to prioritize surveys at the

689 landscape scale. Diversity and Distributions 19:465-480. DOI: 10.1111/j.1472-

$690 \quad$ 4642.2012.00947.x.

691 Tulloch AIT, Sutcliffe P, Naujokaitis-Lewis I, Tingley R, Brotons L, Ferraz KMPMB,

692 Possingham H, Guisan A, Rhodes JR. 2016. Conservation planners tend to ignore

693 improved accuracy of modelled species distributions to focus on multiple threats and

694 ecological processes. Biological Conservation 199:157-171. DOI:

$695 \quad$ 10.1016/j.biocon.2016.04.023. 
696 U.S. Geological Survey, 2016, TopoTools.

697 https://topotools.cr.usgs.gov/GMTED_viewer/gmted2010_global_grids.php [01

698 December, 2018]

699 Uetz, P, Freed, P, Hošek, J (eds.). 2019. The Reptile Database, http://www.reptile-database.org

700 [17 April 2019]

701 Ushey K, McPherson J, Cheng J, Atkins A, Allaire JJ. 2018. packrat: A Dependency

702 Management System for Projects and their R Package Dependencies.

703

704

705

706

707

708

709

710

711

712

713

714

715

716

717

718
Valavi R, Elith J, Lahoz-Monfort J, Guillera-Arroita G. 2018. blockCV: Spatial and environmental blocking for $k$-fold cross-validation.

Venter O, Sanderson EW, Magrach A, Allan JR, Beher J, Jones KR, Possingham HP, Laurance WF, Wood P, Fekete BM, Levy MA, Watson JE. 2016a. Global terrestrial Human Footprint maps for 1993 and 2009. Scientific Data 3: 160067. https://doi.org/10.1038/sdata.2016.67

Venter O, Sanderson EW, Magrach A, Allan JR, Beher J, Jones KR, Possingham HP, Laurance WF, Wood P, Fekete BM, Levy MA, Watson JEM. 2016b. Data from: Global terrestrial Human Footprint maps for 1993 and 2009. Dryad Digital Repository. https://doi.org/10.5061/dryad.052q5.2

Wäldchen J, Mäder P. 2018. Machine learning for image based species identification. Methods in Ecology and Evolution 9:2216-2225. DOI: 10.1111/2041-210X.13075.

Whitaker PB, Shine R. 2000. Sources of Mortality of Large Elapid Snakes in an Agricultural Landscape. Journal of Herpetology 34:121-128. DOI: 10.2307/1565247.

Wickham H. 2007. Reshaping Data with the reshape Package. Journal of Statistical Software 21:1-20.

Peer] reviewing PDF | (2019:06:38771:1:1:NEW 25 Sep 2019) 
719 Wickham H. 2016. ggplot2: Elegant Graphics for Data Analysis. Springer-Verlag New York.

720 Wickham H. 2017. httr: Tools for Working with URLs and HTTP.

721 Wickham H. 2018. stringr: Simple, Consistent Wrappers for Common String Operations.

722 Wickham H. 2019. rvest: Easily Harvest (Scrape) Web Pages.

723 Wickham H, Francois R, Henry L, Müller K. 2017. dplyr: A Grammar of Data Manipulation.

724 Wickham H, Hester J, Ooms J. 2018. xml2: Parse XML.

725 Willson JD, Winne CT. 2016. Evaluating the functional importance of secretive species: A case

726 study of aquatic snake predators in isolated wetlands. Journal of Zoology 298:266-273.

727 DOI: $10.1111 /$ jzo.12311.

728 Wisz MS, Hijmans RJ, Li J, Peterson AT, Graham CH, Guisan A, NCEAS Predicting Species

729 Distributions Working Group †. 2008. Effects of sample size on the performance of

$730 \quad$ species distribution models. Diversity and Distributions 14:763-773. DOI:

731 10.1111/j.1472-4642.2008.00482.x.

732 Yañez-Arenas C, Peterson AT, Mokondoko P, Rojas-Soto O, Martínez-Meyer E. 2014. The use

733 of ecological niche modeling to infer potential risk areas of snakebite in the Mexican

734 State of Veracruz. PLoS ONE 9. DOI: 10.1371/journal.pone.0100957.

735 Yesson C, Brewer PW, Sutton T, Caithness N, Pahwa JS, Burgess M, Gray WA, White RJ, Jones

736 AC, Bisby FA, Culham A. 2007. How Global Is the Global Biodiversity Information

737 Facility? PLoS ONE 2:e1124. DOI: 10.1371/journal.pone.0001124.

738 Yousefi M, Ahmadi M, Nourani E, Behrooz R, Rajabizadeh M, Geniez P, Kaboli M. 2015.

739 Upward Altitudinal Shifts in Habitat Suitability of Mountain Vipers since the Last

740 Glacial Maximum. PLOS ONE 10:e0138087. DOI: 10.1371/journal.pone.0138087. 
741 Zizka A, Silvestro D, Andermann T, Azevedo J, Duarte Ritter C, Edler D, Farooq H, Herdean A,

742 Ariza M, Scharn R, Svanteson S, Wengström N, Zizka V, Antonelli A. 2019.

743 CoordinateCleaner: standardized cleaning of occurrence records from biological

$744 \quad$ collection databases. Methods in Ecology and Evolution. DOI: 10.1111/2041-

$745 \quad 210 X .13152$. 


\section{Table $\mathbf{1}$ (on next page)}

Summary information of GBIF snake records.

\# Species = Number of species appearing in GBIF data, not the actual number of species known to exist across the continent. \# Occurrences = Number of occurrence records in GBIF downloads. Mean occurrences per species $=$ Total number of occurrences records in a continent divided by number of species in GBIF data. SE $=$ Standard error associated with the mean occurrences per species. Area $=$ Area in millions of $\mathrm{km}^{2}$ estimated using Alber's equal area conic projection. Occurrences per $100 \mathrm{~km}^{2}=$ Total number of occurrence records divided by the estimated continental area. 


\begin{tabular}{ccccccc}
\hline Continent & \# Species & \# Occurrences & $\begin{array}{c}\text { Mean } \\
\text { occurrences per } \\
\text { species }\end{array}$ & SE & Area (million $\left.\mathrm{km}^{2}\right)$ & $\begin{array}{c}\text { Occurrences per } \\
100 \mathrm{~km}^{2}\end{array}$ \\
\hline Africa & 513 & 17,108 & 33.35 & 3.38 & 29.89 & 0.006 \\
Asia & 576 & 19,187 & 33.31 & 5.69 & 44.67 & 0.004 \\
Europe & 99 & 42,892 & 433.25 & 169.78 & 8.97 & 0.048 \\
North America & 680 & 157,923 & 232.24 & 33.62 & 24.64 & 0.064 \\
Oceania & 236 & 49,247 & 208.67 & 32.56 & 8.92 & 0.055 \\
South America & 633 & 16,029 & 25.32 & 2.21 & 17.91 & 0.009 \\
\hline
\end{tabular}

1 
Figure 1

Global distribution of all GBIF non-marine snake records displayed against continental divisions.

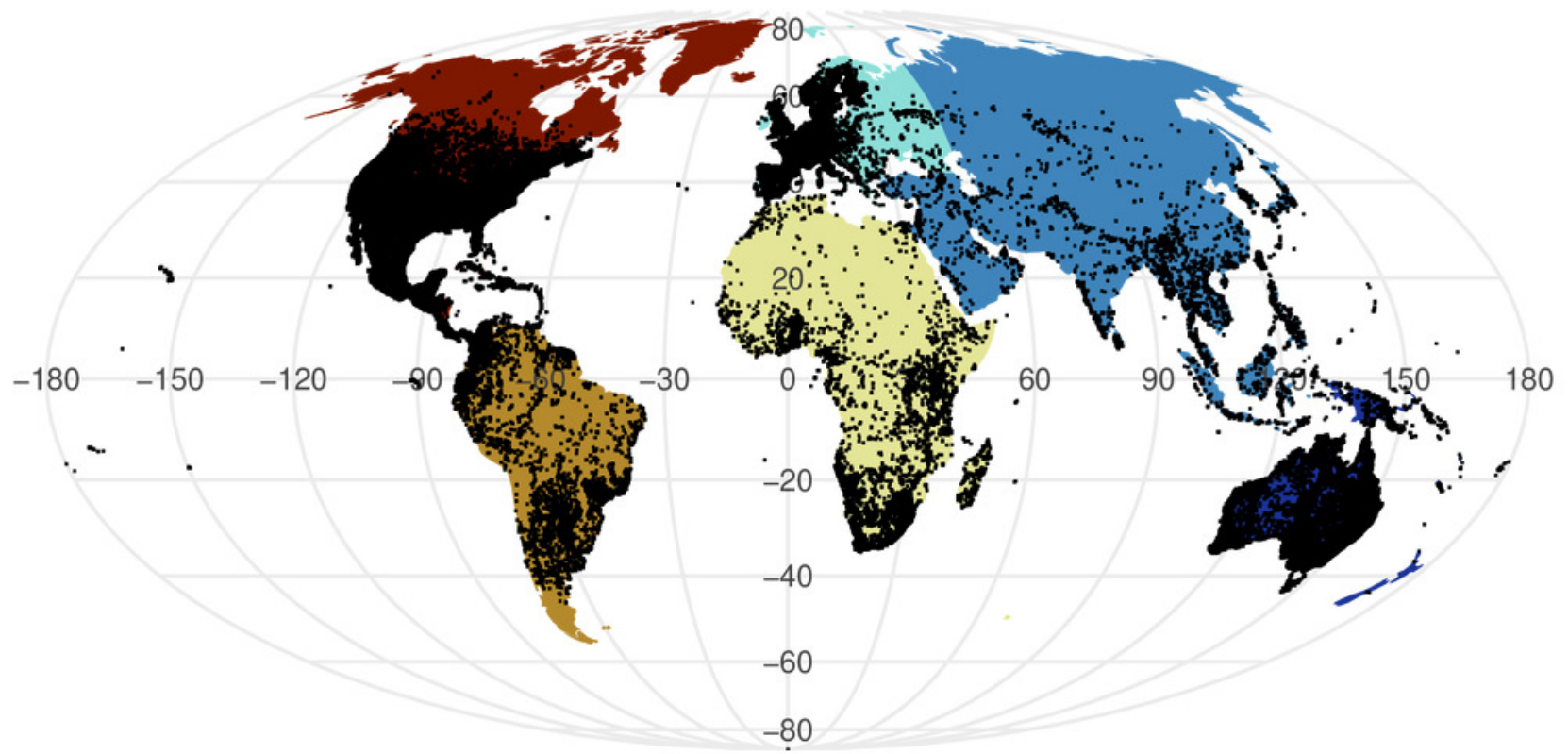


Figure 2

Global distribution of geo-tagged Flickr photos that appeared across all searches

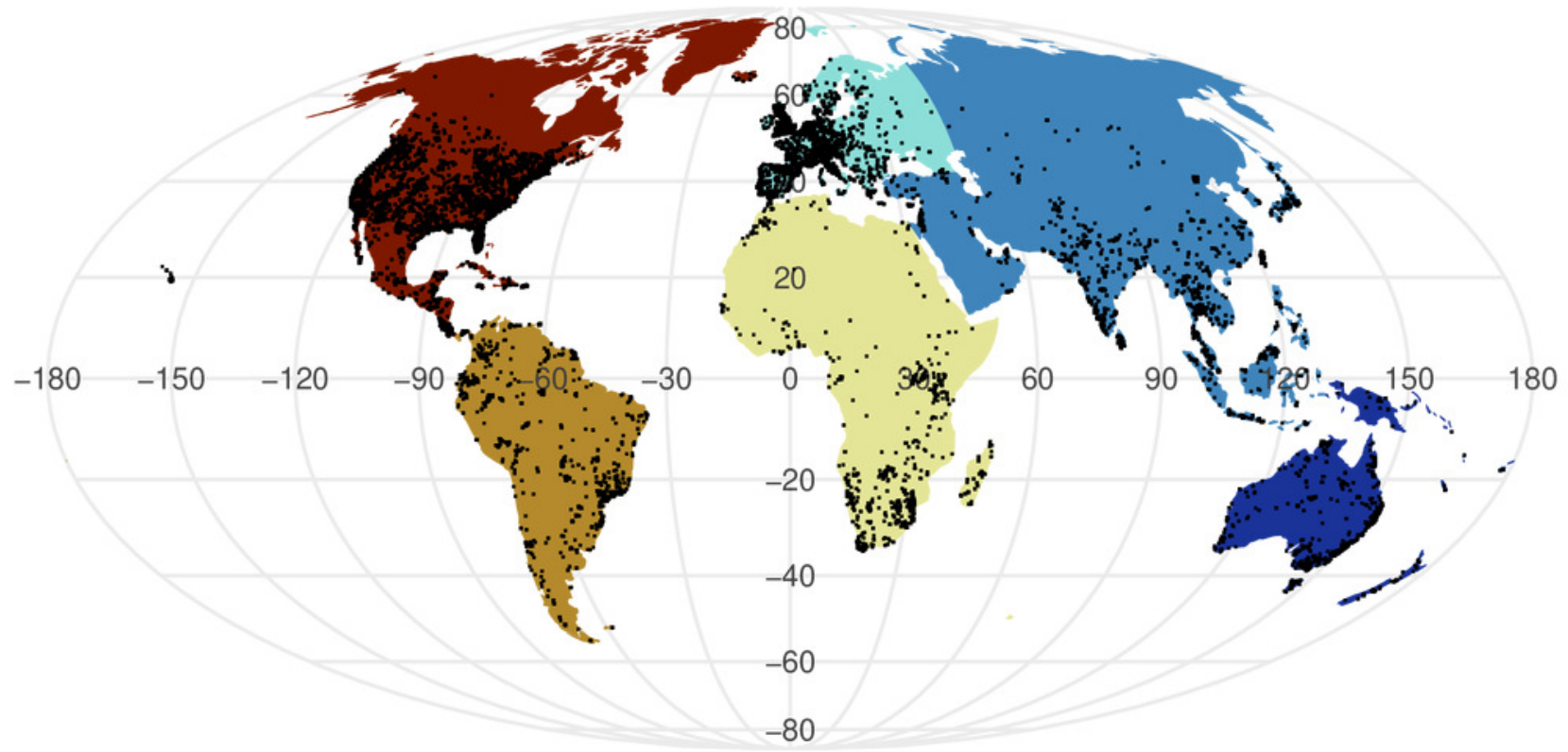




\section{Figure 3}

Number and source of selected species occurrence records.

Species codes in order of appearance: $\mathrm{BiAr}=$ Bitis arietans, $\mathrm{BoKr}=$ Boiga kraepelini, $\mathrm{BoSC}=$ Bothriechis schlegelii, $\mathrm{ChCa}=$ Chironius carinatus, $\mathrm{DePo}=$ Dendroaspis polylepis, EuMu $=$ Eunectes murinus, $\mathrm{OpHa}=$ Ophiophagus hannah, $\mathrm{SiPe}=$ Sinonatrix percarinata, $\mathrm{MaRe}=$ Malayopython reticulatus, $\mathrm{EcCo}=$ Echis coloratus, $\mathrm{BuFa}=$ Bungarus fasciatus, $\mathrm{HyGi}=$ Hydrodynastes gigas, $\mathrm{CoRa}=$ Coelognathus radiatus, $\mathrm{BoCy}=$ Boiga cynodon, $\mathrm{EnEn}=$ Enhydris enhydris, $\mathrm{CaRh}=$ Calloselasma rhodostoma, $\mathrm{AtNi}=$ Atheris nitschei, $\mathrm{ApBo}=$ Aplopeltura boa.

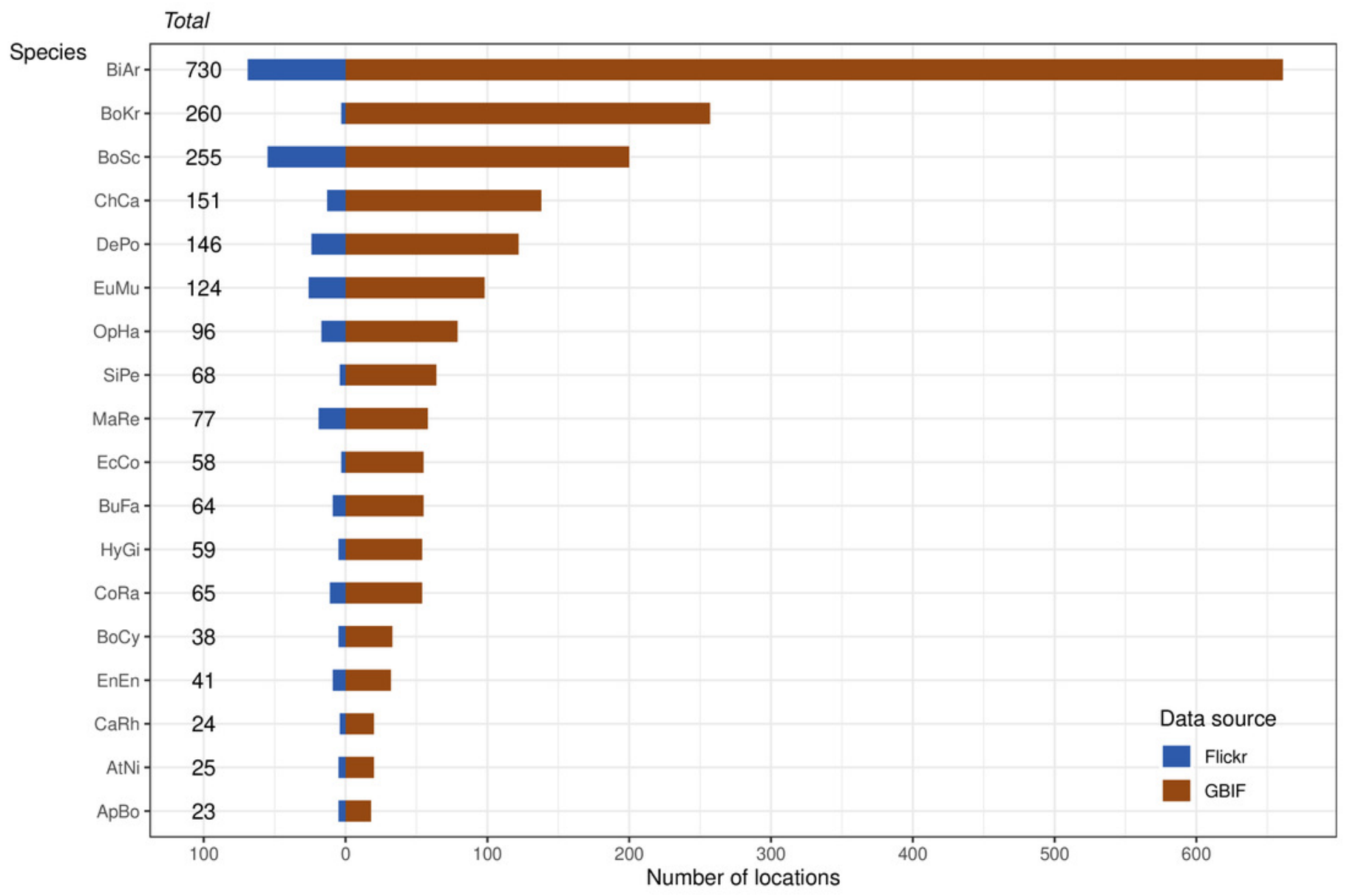




\section{Figure 4}

Relationship between number of occurrences and the minimum convex polygon (MCP) area cover by occurrence points.

Minimum convex polygon are clipped to exclude oceans. Both scales are presented as logs to make individual species visible. Species codes from left to right: BoKr = Boiga kraepelini, $\mathrm{CaRh}=$ Calloselasma rhodostoma, $\mathrm{AtNi}=$ Atheris nitschei, $\mathrm{BoSc}=$ Bothriechis schlegelii, $\mathrm{ApBo}=$ Aplopeltura boa, $\mathrm{SiPe}=$ Sinonatrix percarinata, $\mathrm{BoCy}=$ Boiga cynodon, $\mathrm{MaRe}=$ Malayopython reticulatus, $\mathrm{CoRa}=$ Coelognathus radiatus, $\mathrm{BuFa}=$ Bungarus fasciatus, EnEn $=$ Enhydris enhydris, $\mathrm{DePo}=$ Dendroaspis polylepis, $\mathrm{EcCo}=$ Echis coloratus, $\mathrm{OpHa}=$ Ophiophagus hannah, $\mathrm{HyGi}=$ Hydrodynastes gigas, $\mathrm{ChCa}=$ Chironius carinatus, $\mathrm{EuMu}=$ Eunectes murinus, BiAr $=$ Bitis arietans. 


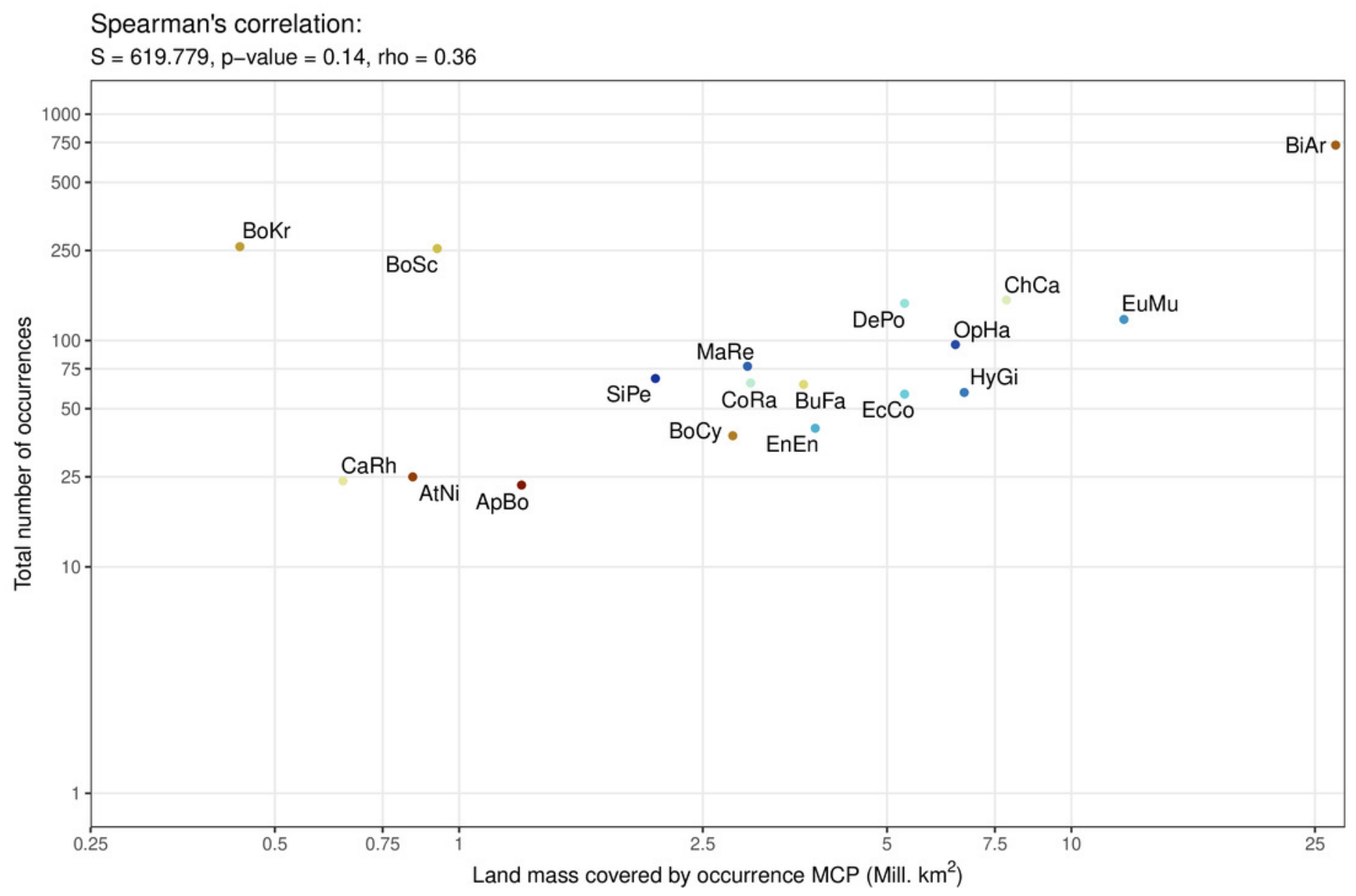




\section{Figure 5}

Receiver Operating Characteristic results for the three models when tested against the three independent test datasets.

(A) GBIF random sample. (B) GBIF geo-independent sample. (C) Flickr data. Species codes in alphabetical order: $\mathrm{ApBo}=$ Aplopeltura boa, $\mathrm{AtNi}=$ Atheris nitschei, $\mathrm{BiAr}=$ Bitis arietans, BoCy = Boiga cynodon, BoKr = Boiga kraepelini, BoSc = Bothriechis schlegelii, BuFa = Bungarus fasciatus, $\mathrm{CaRh}=$ Calloselasma rhodostoma, $\mathrm{ChCa}=$ Chironius carinatus, $\mathrm{CoRa}=$ Coelognathus radiatus, DePo $=$ Dendroaspis polylepis, EcCo $=$ Echis coloratus, EnEn $=$ Enhydris enhydris, EuMu = Eunectes murinus, $\mathrm{HyGi}=$ Hydrodynastes gigas, $\mathrm{MaRe}=$ Malayopython reticulatus, $\mathrm{OpHa}=$ Ophiophagus hannah, $\mathrm{SiPe}=$ Sinonatrix percarinata.

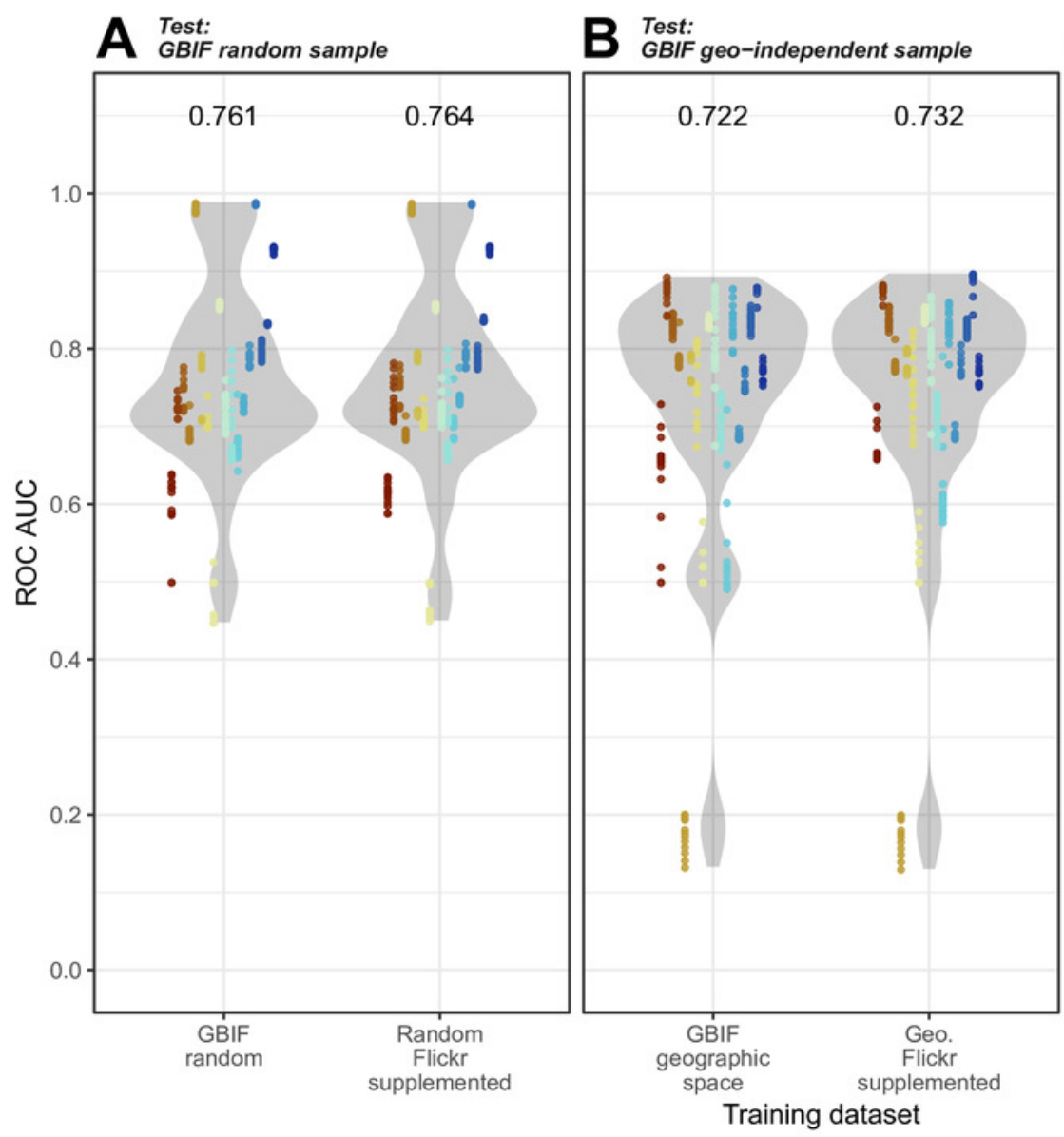

C. Test:

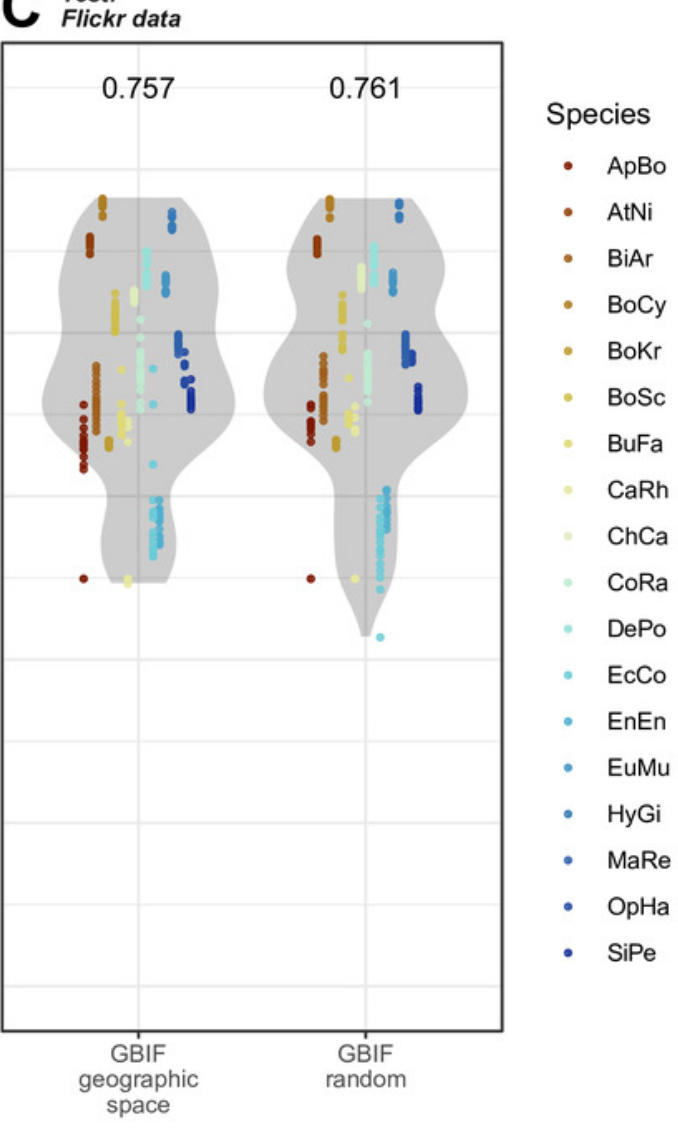


Figure 6

Precision-Recall results for the three models when tested against the three independent test datasets.

(A) GBIF random sample. (B) GBIF geo-independent sample. (C) Flickr data. Species codes in alphabetical order: $\mathrm{ApBo}=$ Aplopeltura boa, $\mathrm{AtNi}=$ Atheris nitschei, $\mathrm{BiAr}=$ Bitis arietans, $\mathrm{BoCy}=$ Boiga cynodon, $\mathrm{BoKr}=$ Boiga kraepelini, $\mathrm{BoSc}=$ Bothriechis schlegelii, BuFa $=$ Bungarus fasciatus, $\mathrm{CaRh}=$ Calloselasma rhodostoma, $\mathrm{ChCa}=$ Chironius carinatus, $\mathrm{CoRa}=$ Coelognathus radiatus, DePo $=$ Dendroaspis polylepis, EcCo $=$ Echis coloratus, EnEn $=$ Enhydris enhydris, EuMu = Eunectes murinus, $\mathrm{HyGi}=$ Hydrodynastes gigas, $\mathrm{MaRe}=$ Malayopython reticulatus, $\mathrm{OpHa}=$ Ophiophagus hannah, $\mathrm{SiPe}=$ Sinonatrix percarinata.

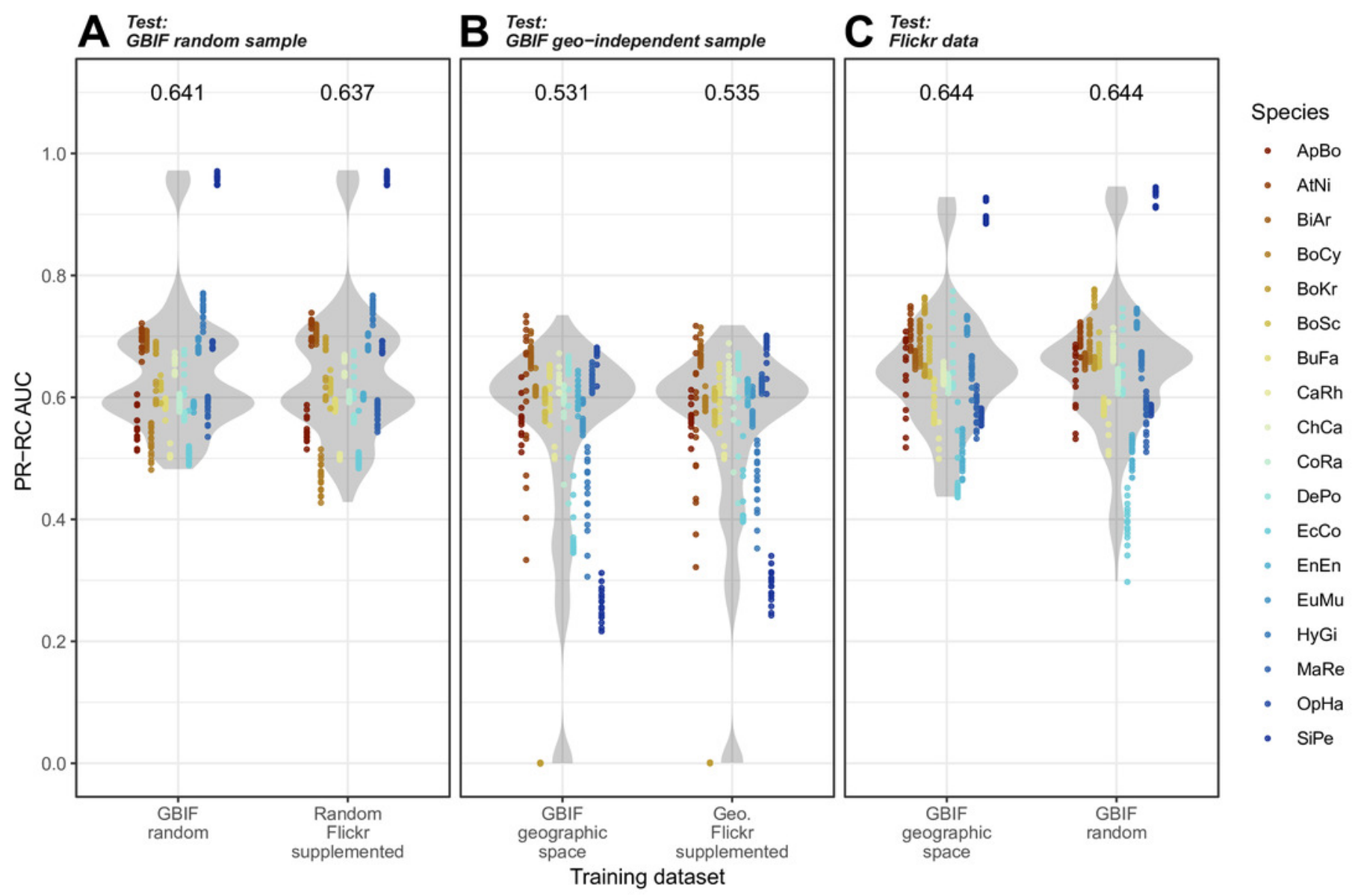


Figure 7

Schoener's D measure of niche overlap for models trained on GBIF-only and Flickr supplemented datasets

Right-hand side values show the overall niche overlap mean per species and the standard error. Species codes top to bottom: BoCy $=$ Boiga cynodon, $\mathrm{EnEn}=$ Enhydris enhydris, $\mathrm{AtNi}=$ Atheris nitschei, $\mathrm{OpHa}=$ Ophiophagus hannah, $\mathrm{CoRa}=$ Coelognathus radiatus, $\mathrm{SiPe}=$ Sinonatrix percarinata, $\mathrm{EcCo}=$ Echis coloratus, $\mathrm{MaRe}=$ Malayopython reticulatus, $\mathrm{EuMu}=$ Eunectes murinus, $\mathrm{HyGi}=$ Hydrodynastes gigas, $\mathrm{BiAr}=$ Bitis arietans, $\mathrm{ApBo}=$ Aplopeltura boa, $\mathrm{DePo}=$ Dendroaspis polylepis, BoKr $=$ Boiga kraepelini, $\mathrm{BoSc}=$ Bothriechis schlegelii, $\mathrm{ChCa}=$ Chironius carinatus, BuFa $=$ Bungarus fasciatus, $\mathrm{CaRh}=$ Calloselasma rhodostoma .

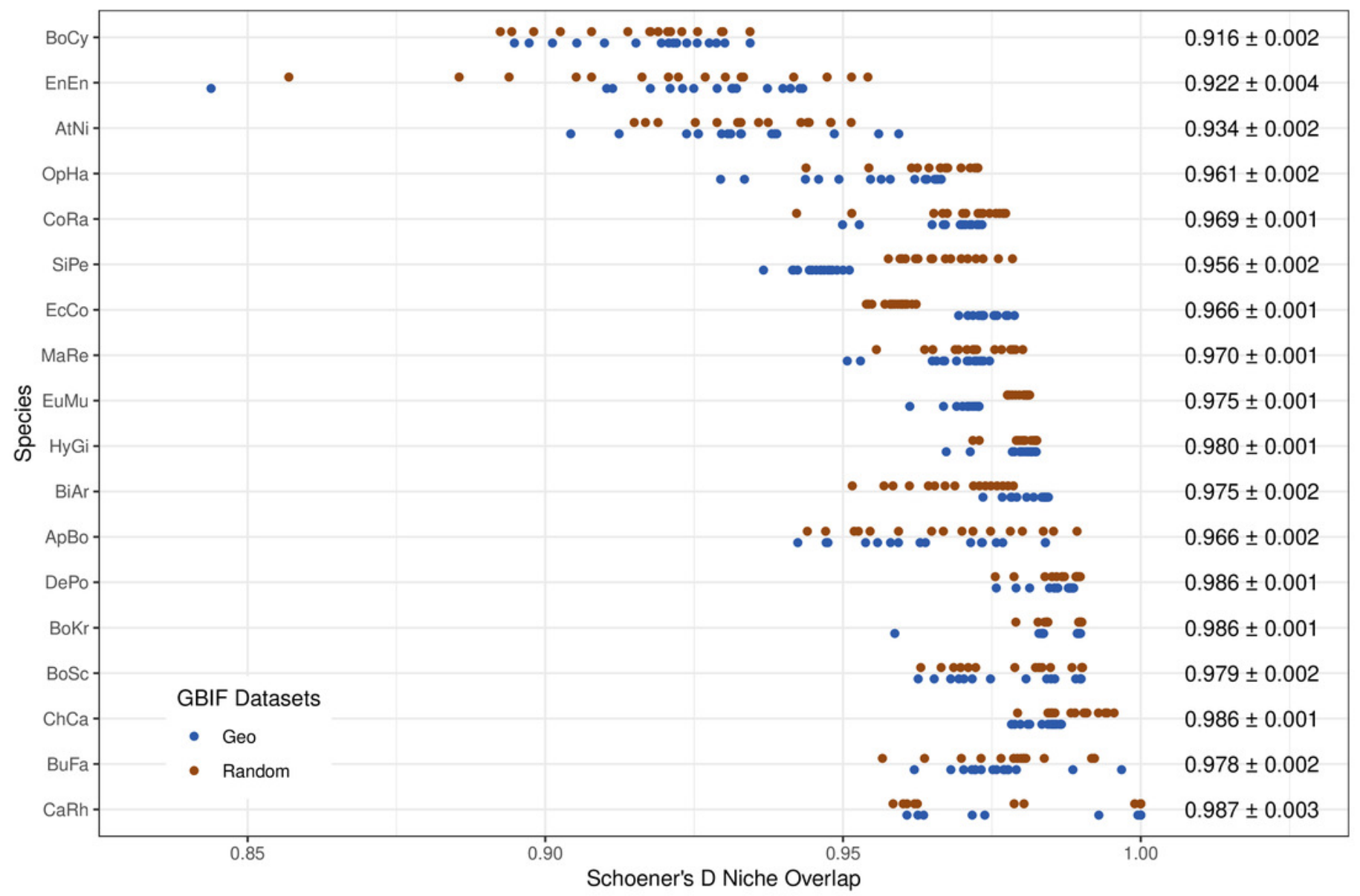

